\title{
Cerebrospinal fluid detection of interleukin-1 $\beta$ in phase of remission predicts disease progression in multiple sclerosis
}

\author{
Silvia Rossi ${ }^{1,2+}$, Valeria Studer ${ }^{1,2+}$, Caterina Motta ${ }^{1,2}$, Giorgio Germani ${ }^{1,2}$, Giulia Macchiarulo ${ }^{1,2}$, Fabio Buttari ${ }^{1,2}$, \\ Raffaele Mancino ${ }^{3}$, Maura Castelli ${ }^{1,2}$, Valentina De Chiara ${ }^{1,2}$, Sagit Weiss ${ }^{1,2}$, Gianvito Martino ${ }^{4}$, Roberto Furlan ${ }^{4}$ \\ and Diego Centonze ${ }^{1,2^{*}}$
}

\begin{abstract}
Background: Absence of clinical and radiological activity in relapsing-remitting multiple sclerosis (RRMS) is perceived as disease remission. We explored the role of persisting inflammation during remission in disease evolution.

Methods: Cerebrospinal fluid (CSF) levels of interleukin $1 \beta$ (IL-1 $\beta$ ), a major proinflammatory cytokine, were measured in 170 RRMS patients at the time of clinical and radiological remission. These patients were then followed up for at least 4 years, and clinical, magnetic resonance imaging (MRI) and optical coherence tomography (OCT) measures of disease progression were recorded.

Results: Median follow-up of RRMS patients was 5 years. Detection of CSF IL-1 $1 \beta$ levels at the time of remission did not predict earlier relapse or new MRI lesion formation. Detection of IL-1 $\beta$ in the CSF was instead associated with higher progression index (PI) and Multiple Sclerosis Severity Scale (MSSS) scores at follow-up, and the number of patients with sustained Expanded Disability Status Scale (EDSS) or Multiple Sclerosis Functional Composite worsening at follow-up was higher in individuals with detectable levels of IL-1 $\beta$. Patients with undetectable IL-1 $\beta$ in the CSF had significantly lower PI and MSSS scores and a higher probability of having a benign MS phenotype. Furthermore, patients with undetectable CSF levels of IL-1 $\beta$ had less retinal nerve fiber layer thickness and macular volume alterations visualized by OCT compared to patients with detectable IL-1 $\beta$.
\end{abstract}

Conclusions: Our results suggest that persistence of a proinflammatory environment in RRMS patients during clinical and radiological remission influences midterm disease progression. Detection of IL-1 $\beta$ in the CSF at the time of remission appears to be a potential negative prognostic factor in RRMS patients.

Keywords: Cerebrospinal fluid, Cytokines, Inflammation, Disability, Neurodegeneration, Remission

\section{Background}

Relapsing-remitting multiple sclerosis (RRMS) was originally described as a disease characterized by alternating symptomatic and asymptomatic periods, which were perceived to reflect, respectively, disease activity and remission. With the advent of conventional and, later, unconventional

\footnotetext{
* Correspondence: centonze@uniroma2.it

${ }^{\dagger}$ Equal contributors

${ }^{1}$ Clinica Neurologica, Dipartimento di Medicina dei Sistemi, Università Tor Vergata, Via Montpellier 1, 00133 Rome, Italy

${ }^{2}$ Fondazione Santa Lucia/Centro Europeo per la Ricerca sul Cervello (CERC), Via del Fosso di Fiorano 64, 00143 Rome, Italy

Full list of author information is available at the end of the article
}

magnetic resonance imaging (MRI) technologies, it appeared that the disease could be active in asymptomatic patients, leading to an extension of diagnostic criteria for RRMS and response to treatment to radiological parameters. Hints suggesting that disability in RRMS patients has additional causes beyond clinical and radiological relapses came from observations in patients with brain atrophy and reduction of $N$-acetyl aspartate, a marker for axonal loss. Brain atrophy appeared to progress in patients who were not active [1], whereas brain atrophy progression [2] and reduction of $\mathrm{N}$-acetyl aspartate [3] correlated with disability progression, indicating that disease severity was not 
determined by relapses only. In line with these observations, researchers who have conducted pathological studies have reported synapse, neuronal and glial loss independent of demyelination [3-9]. Further, investigators have reported evidence of neuronal and glial excitotoxicity in MS [10-12], a central nervous system (CNS)-specific cellular death pathway triggered by an excess of excitatory glutamate signaling. In this respect, we have recently demonstrated that, during MS relapses, cerebrospinal fluid (CSF) concentrations of the proinflammatory cytokine interleukin $1 \beta$ (IL-1 $\beta$ ) increase to a level high enough to boost excitatory transmission and excitotoxic damage in neurons [13]. These premises prompted us to explore whether persistence of IL- $1 \beta$ signaling during remission phases of MS could affect the severity of the disease. In accord with this hypothesis, our results show that detection of the proinflammatory cytokine IL-1 $\beta$ in the CSF of early RRMS patients at the time of remission was associated with pronounced neuronal damage and accumulating disability in the following years.

\section{Methods}

This study was conducted in compliance with the principles of the Declaration of Helsinki and was approved by the Ethical Committee of the Policlinico Università Tor Vergata in Rome. All the participants gave their written informed consent to be included in the study.

\section{Multiple sclerosis patients and cerebrospinal fluid collection}

A total of 170 central-southern Italian subjects with a diagnosis of RRMS according to the 2005 McDonald criteria [14] were included in this study (Figure 1). CSF was collected at the time of diagnosis from patients in clinical and radiological remission. In particular, patients who had experienced a clinical relapse within the preceding 60 days or had shown gadolinium (Gd)-enhanced lesions or new lesions visualized by T2-weighted MRI were excluded. Relapses were defined as the development of new or recurrent neurological symptoms not associated with fever or infection lasting for at least 24 hours. Lumbar puncture and brain MRI were performed within 24 hours of each other. Blood sample collection, CSF withdrawal and clinical assessments were performed at the MS Center of the Tor Vergata University Hospital of Rome by MS specialist neurologists. To be recruited into the study, patients had to have had at least 4 years of clinical, MRI and optical coherence tomography (OCT) follow-up after CSF collection. In addition, only patients clinically in the remitting phase of MS and without MRI evidence of new or active lesions at the time of CSF withdrawal were considered for inclusion in the present investigation. Accordingly, only transient elevation of proinflammatory cytokines has been reported during MRI or clinical reactivation in MS patients $[13,15]$. Demographic and clinical information were derived from medical records. MS disease onset was defined as the first episode of focal neurological dysfunction indicative of MS. Disease duration was estimated as the number of years from onset to the most recent assessment of disability. The Bayesian Risk Estimate for Multiple Sclerosis (BREMS) score was calculated using gender, age at onset and clinical events during the first year of disease to identify individual risk of secondary progression [16]. At the time of confirmed diagnosis, all MS patients had started disease-modifying therapy (daily glatiramer acetate $20 \mathrm{mg}$ subcutaneously (s.c.), interferon $\beta$-1a (IFN- $\beta$-1a) $44 \mu$ g s.c. three times weekly, IFN- $\beta-1 \mathrm{a} 30 \mu \mathrm{g}$ intramuscularly or IFN- $\beta-1 \mathrm{~b}$

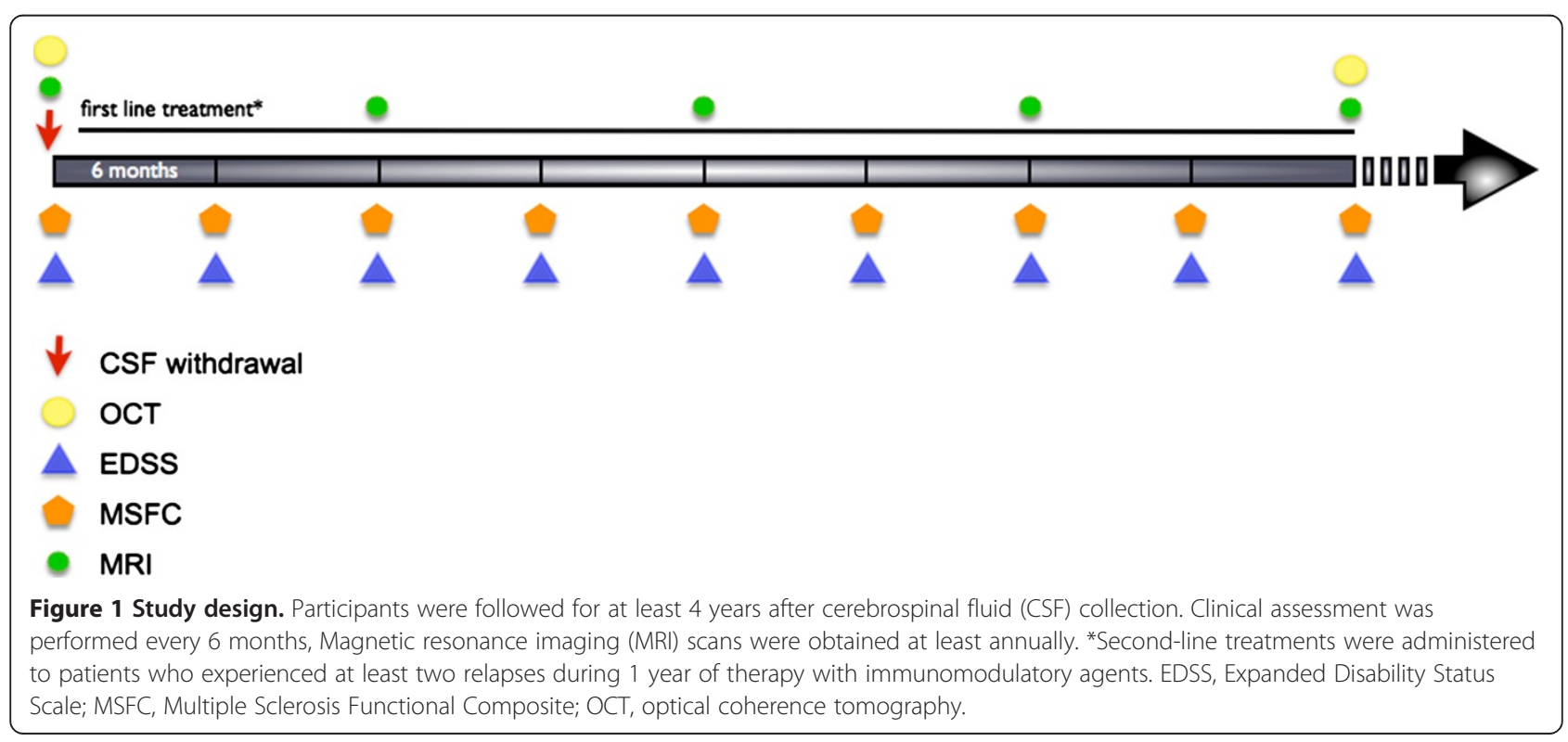


$250 \mu \mathrm{g}$ s.c. every other day). Mitoxantrone $\left(12 \mathrm{mg} / \mathrm{m}^{2}\right.$ intravenously (i.v.) every 3 months with a lifetime maximum of $140 \mathrm{mg} / \mathrm{m}^{2}$ ), natalizumab (300 mg i.v. every 4 weeks) and fingolimod ( $0.5 \mathrm{mg}$ by mouth every day) were considered as second-line treatments for patients who experienced at least two relapses during 1 year of therapy with other approved immunomodulatory agents. The annualized relapse rate (ARR) was defined as the number of relapses per year. In addition, the number of relapses in the first 2 years of the disease course and the time until the first relapse were used as clinical indexes of inflammatory activity.

\section{Disability assessment}

Disability was determined by a specially trained (Neurostatus: Available at http://www.neurostatus.net/index. php?file=start) and certified examining neurologist using the Expanded Disability Status Scale (EDSS), a ten-point disease severity score derived from nine ratings for individual neurological domains [17]. The EDSS score, evaluated every 6 months after diagnosis, was used in combination with disease duration to calculate two measures of disease severity: the progression index (PI) and the Multiple Sclerosis Severity Scale (MSSS). The PI was defined as EDSS divided by disease duration. The MSSS is an algorithm that relates EDSS scores to distribution of disability in patients with comparable disease durations [18]. Sustained EDSS progression was defined as a one-point increase persisting for at least 6 months. The Multiple Sclerosis Functional Composite (MSFC) score [19], obtained on the same day as the EDSS score, consists of three domains in separate measurements: scoring ambulation (Timed Walk Test), upper-extremity function (Nine Hole Peg Test) and cognition (Paced Auditory Serial Addition Test). These separate quantitative scores were used in our analyses. Disability progression using the MSFC score was defined as a sustained change of at least $20 \%$ from baseline for any of the three components of the MSFC. Our definition of disability progression also required worsening that persisted for at least 6 months. EDSS and MSFC scores were taken into account for the assessment of disability progression when obtained at least 30 days since stabilization and/or resolution of a previous relapse and/or corticosteroid treatment.

\section{Optical coherence tomography}

A medical history with respect to visual symptoms was obtained from all MS participants. Self-report and physician report were confirmed by record review. A subset of RRMS patients $(n=118)$ without a history of optic neuritis and ophthalmological disease underwent measurement of retinal nerve fiber layer (RNFL) thickness and macular volume (MV) for both eyes using Stratus OCT System software version 4.0.2 (Carl Zeiss Meditec,
Jena, Germany) [20]. Briefly, for MV, retinal thickness was measured automatically as the distance between the vitreoretinal interface and the anterior boundary of the retinal pigment epithelium. Stratus OCT images were generated using the fast mapping scan protocol, consisting of six radial scans spaced $30^{\circ}$ apart, with each scan measuring $6 \mathrm{~mm}$ in length. Each image had a resolution of $10 \mu \mathrm{m}$ axially and $20 \mu \mathrm{m}$ transversally. All Stratus OCT images had a signal strength of $6 \mu \mathrm{m}$. RNFL thickness measurements were read from the automated measurements generated by the machine using Fast RNFL analysis. Scanning was performed after pharmacological dilation. Average RNFL thickness for $360^{\circ}$ around the optic disc was recorded. Values were adjusted for age. One randomly chosen eye from each participant was included in the study. Testing was performed by trained technicians experienced in examination of patients for research studies, and patients wore their habitual eyeglasses or contact lenses for distance correction.

\section{MRI}

MRI scans (1.5 T), which consisted of dual-echo proton density, fluid-attenuated inversion recovery, T2-weighted spin-echo images (T2-WI) and pre- and post-contrastenhanced T1-weighted spin-echo images (T1-WI), were analyzed by a neuroradiologist who was unaware of the patient's clinical details. A new $\mathrm{Gd}+(0.2 \mathrm{ml} / \mathrm{kg}$, intravenously) lesion was defined as a typical area of hyperintense signaling on post-contrast-enhanced T1-WI. A new or newly enlarging lesion on T2-WI was defined as a rounded or oval lesion arising from an area previously considered as normal-appearing brain tissue and/or showing an identifiable increase in size from a previously stable-appearing lesion. An active scan was defined as one showing any new, enlarging or recurrent lesions on postcontrast-enhanced T1-WI and T2-WI. T2-WI lesion volume was determined by manual tracing.

\section{Measurement of IL-1 $\beta$ in cerebrospinal fluid}

CSF was centrifuged and immediately stored at $-80^{\circ} \mathrm{C}$ until analyzed using a Bio-Plex multiplex cytokine assay (Bio-Rad Laboratories, Hercules, CA, USA) according to the manufacturer's instructions. Concentrations of IL-1 $\beta$ (171-A11127; Bio-Rad Laboratories) were calculated according to a standard curve generated for each target and expressed in picograms per milliliter. When the cytokine concentrations were below the detection threshold, they were assumed to be $0 \mathrm{pg} / \mathrm{ml}$.

\section{Statistical analysis}

Participants with MS were divided into two groups according to the detectability (+ group) or undetectability (- group) of IL-1 $\beta$ in the CSF. Differences among groups were compared by univariate analysis using Student's 
$t$-test or Mann-Whitney $U$ test for continuous variables and Fisher's exact test or $x^{2}$ test for categorical variables. Survival curves were analyzed using a logrank (Mantel-Cox) test. Logistic regression models were constructed for the disability as outcome. We estimated the degree of disability by means of the dichotomous EDSS (cutoff point of 3.0 and 4.0, at which, respectively, significant clinical disability and restriction in ambulation start to be appreciated). Four variables (years with disease, age at the time of blood draw, gender and cytokine detection) were included as predictor variables. Disability progression was also assessed by sustained MSFC worsening. The analyses were replicated with the use of second-line treatments taken into consideration as a covariate. In a further model, benign MS status, defined by an EDSS score less than 3.015 years or more after disease onset [21], was included as an outcome variable and BREMS score, age and cytokine detection as predictors. Two-way analysis of variance was performed to analyze the main effects of two conditions (cytokine detection versus disease duration) on the dependent variables (ophthalmologic variables) and their interactions. A $P$-value less than 0.05 was considered statistically significant.

\section{Results}

\section{Patient characteristics}

The demographic features and clinical characteristics of RRMS patients are shown in Table 1 . The median followup duration was 5 years. The minimum and maximum last EDSS values were 0 and 6.5, respectively. All patients had received immunomodulatory treatment during the course of their disease. All of them received first-line treatments since the time of their diagnosis as specified in the Methods section. Some patients (52\%) had two immunomodulatory treatments. Patient characteristics according to CSF IL- $1 \beta$ contents are shown in Table 1 . The mean EDSS was lower among patients with undetectable IL-1 $\beta$ $(P<0.01)$.

\begin{tabular}{|c|c|c|c|c|}
\hline \multirow[t]{2}{*}{ Characteristics } & \multirow[b]{2}{*}{ Total } & \multicolumn{3}{|l|}{ IL-1 $\beta$} \\
\hline & & + & - & $P$-value \\
\hline Number & 170 & 77 & 93 & \\
\hline Gender (M/F) & $62 / 108$ & $27 / 50$ & $35 / 58$ & 0.75 \\
\hline Age (years) & $36.3 \pm 9.5$ & $37.8 \pm 10.1$ & $35.1 \pm 8.8$ & 0.07 \\
\hline Disease duration (years) & $10.5 \pm 5.3$ & $10.9 \pm 5.9$ & $10.2 \pm 4.8$ & 0.39 \\
\hline EDSS & $2.2 \pm 1.7$ & $2.8 \pm 1.9$ & $1.7 \pm 1.4$ & $<0.01$ \\
\hline BREMS & $0.34 \pm 0.9$ & $0.47 \pm 1.0$ & $0.23 \pm 0.8$ & 0.10 \\
\hline
\end{tabular}

${ }^{+}+$, detectable; -, undetectable; BREMS, Bayesian Risk Estimate for Multiple Sclerosis; EDSS, Expanded Disability Status Scale; F, female; IL-1 $\beta$, interleukin $1 \beta$; $M$, male. Data are mean \pm SD.
Lack of association between prospective disease activity and cerebrospinal fluid IL-1 $\beta$ level at time of remission

We have previously shown enhanced free IL-1 $\beta$ levels and IL-1 $\beta$-mediated neurotoxicity in the CSF of patients with active MS and Gd + lesions [13]. In the current study, we analyzed clinical and MRI indexes of inflammatory activity in RRMS patients, whom we stratified by CSF detection of IL-1 $\beta$ during the clinical and radiological remission phase. No significant differences were observed for either examined parameter. In particular, the mean ARR in the first 4 years after diagnosis (IL-1 $\beta+$ : $0.44 \pm 0.32$ versus IL-1 $\beta-$ : $0.45 \pm 0.34$ ), the number of participants with two or more clinical relapses within the first 2 years after the disease diagnosis (IL-1 $\beta+: 37.6 \%$ versus IL-1 $\beta-$ : $38.7 \%$ ), the number of participants with an MRI scan showing active MS within the first 2 years after the disease diagnosis (IL-1 $\beta+$ : $45.4 \%$ versus IL-1 $\beta-$ : $44.9 \%$ ), the number of patients prescribed a second-line treatment (IL-1 $\beta+: 28.5 \%$ versus IL-1 $\beta$-: $26.8 \%)$ and T2-WI-detected lesion volume (IL-1 $\beta+: 8,741.8 \pm 2,674.5 \mathrm{~mm}^{3}$ versus IL-1 $\beta-:$ 8,486.4 \pm $2,903.9 \mathrm{~mm}^{3}$ ) were similar $(P>0.05$ for each comparison). In line with these findings, no significant differences between the groups were revealed by survival analysis for time to first clinical relapse $(P>0.05)$ (Figure $2 \mathrm{~A}$ ) and the time to detection of an active MRI scan since diagnosis $(P>0.05)$ (Figure 2B).

\section{Association between prospective disease progression and} cerebrospinal fluid IL-1 $\beta$ detection at time of remission When we compared patients with undetectable vs. those with detectable CSF IL-1 $\beta$ levels at baseline, we found that mean PI and MSSS scores were significantly lower among participants with undetectable IL- $1 \beta(P<0.01$ for both parameters) (Figures $3 \mathrm{~A}$ and $3 \mathrm{~B}$ ). The number of participants with sustained worsening according to EDSS or MSFC score at follow-up was higher in the IL- $1 \beta+$ group (EDSS: $41.5 \%$ versus $25.8 \%, P=0.03$; MSFC: $50.6 \%$ versus $32.2 \%, P=0.02$ ) (Figures $3 \mathrm{C}$ and $3 \mathrm{D}$ ). By applying multiple logistic regression analysis with dichotomous EDSS score as the response variable and the variables described in the Methods section as predictors, the probability of reaching an EDSS score of 3.0 at follow-up was significantly affected by the presence of IL- $1 \beta$ in CSF and by the duration of the disease (Table 2). The analysis replicated using an EDSS score of 4.0 as the cutoff confirmed the association between IL-1 $\beta$ detection in CSF in patients in remission and the probability of reaching higher EDSS values at the follow-up examination (Table 3). Similar results were obtained when MSFC worsening was included as an outcome variable. In fact, the logistic regression predicted that, at equal values for age, gender and disease duration, the probability of disability progression according to MSFC score increased in the IL- $1 \beta+$ group (coefficient of correlation: 

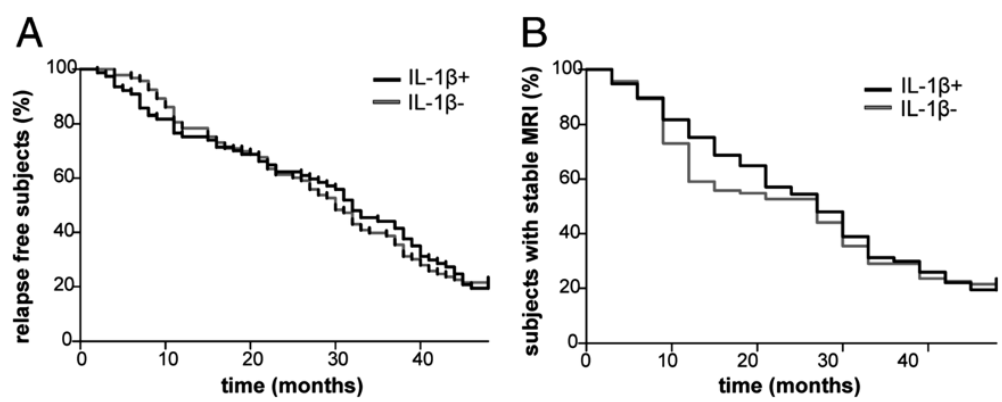

Figure 2 Interleukin $1 \beta$ does not influence disease inflammatory activity in relapsing-remitting multiple sclerosis. (A) and (B) Survival analyses for the time to first clinical relapse (A) and the time to detecting an active magnetic resonance imaging (MRI) scan since diagnosis (B), among participants with detectable or undetectable levels of interleukin $1 \beta(\mathrm{IL}-1 \beta)$ in the cerebrospinal fluid. No significant differences were observed.

0.75, SE: 0.33 , odds ratio (OR): $2.13,95 \%$ confidence interval $(\mathrm{CI}): 1.11$ to $4.09, P=0.02)$. The analyses were replicated taking into consideration the use of secondline treatments as a covariate. In addition, using the same model, the presence of IL-1 $\beta$ in CSF significantly affected the probability of reaching an EDSS score of 3.0

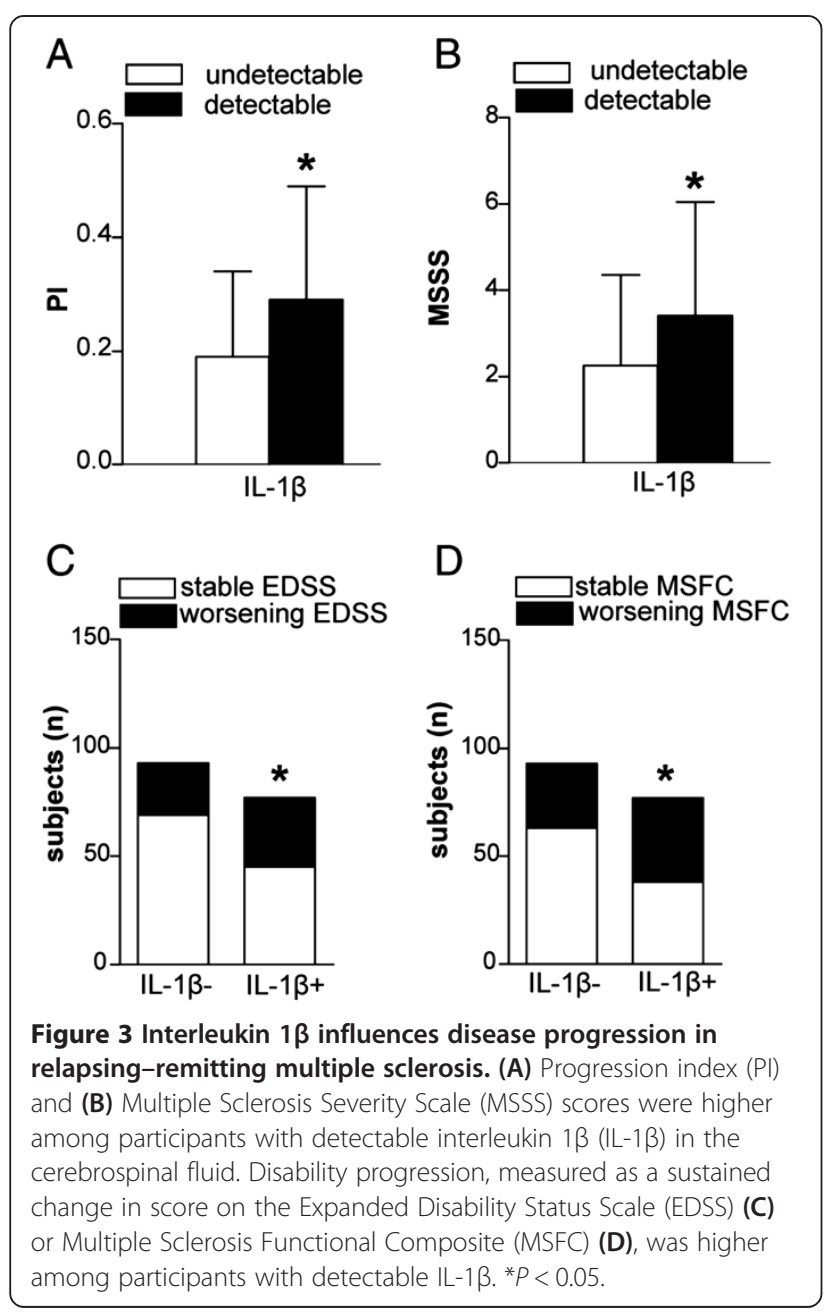

(coefficient of correlation: 1.47, SE: 0.42, OR: 4.34, 95\% CI: 1.93 to $9.83, P<0.001$ ), EDSS score of 4.0 (coefficient of correlation: 1.41, SE: 0.45, OR: 4.12, 95\% CI: 1.69 to 10.02, $P=0.001$ ) and MSFC worsening (coefficient of correlation: 0.79 , SE: 0.35 , OR: $2.21,95 \% \mathrm{CI}: 1.10$ to 4.41, $P=0.02$ ).

Patients with high BREMS scores are considered at very high risk of secondary progression, and patients with low BREMS scores are very likely to remain progression-free [16]. Undetectable IL-1 $\beta$ significantly predicted benign MS at equal BREMS score values (coefficient of correlation: 3.28 , SE: 1.51 , OR: $26.61,95 \%$ CI: 1.37 to 515.47 , $P=0.03)$.

\section{Association between cerebrospinal fluid IL-1 $\beta$ level detection and neuronal damage}

We also investigated the possible relationship between CSF IL- $1 \beta$ content at the time of the clinical and radiological remission phase at baseline and OCT parameters at follow-up in RRMS patients with the same disease duration (disease duration $\leq 7$ years: IL- $1 \beta+(n=23)$, IL$1 \beta-(n=23)$; disease duration $>7$ years: IL- $1 \beta+(n=33)$, IL-1 $\beta-(n=39))$. A significant main effect of CSF IL-1 $\beta$ content was revealed by analyzing both RNFL thickness $(\mathrm{F}=8.08, P=0.005)$ and $\mathrm{MV}(\mathrm{F}=23.74, P<0.0001)$, indicating damage to axonal and neuronal structures among

Table 2 Logistic regression data using Expanding Disability Status Scale score $\geq \mathbf{3 . 0}$ as the response variable $^{a}$

\begin{tabular}{llllll}
\hline $\begin{array}{l}\text { Predictor } \\
\text { variable }\end{array}$ & $\begin{array}{l}\text { Coefficient of } \\
\text { correlation }\end{array}$ & SE & OR & $\begin{array}{l}\text { 95\% confidence } \\
\text { interval }\end{array}$ & P-value \\
\hline $\begin{array}{l}\text { IL-1 } \beta \\
\text { detection }\end{array}$ & 1.22 & 0.35 & 3.38 & 1.69 to 6.79 & $<0.001$ \\
Age & 0.01 & 0.02 & 1.01 & 0.97 to 1.05 & 0.59 \\
$\begin{array}{l}\text { Gender (M) } \\
\text { Disease }\end{array}$ & 0.64 & 0.36 & 1.90 & 0.93 to 3.87 & 0.07 \\
duration & 0.09 & 0.03 & 1.09 & 1.02 to 1.17 & 0.01 \\
\hline
\end{tabular}

aIL-1 $\beta$, interleukin $1 \beta ;$ OR, odds ratio; SE, standard error. 
Table 3 Logistic regression using Expanding Disability Status Scale score $\geq \mathbf{4 . 0}$ as the response variable ${ }^{a}$

\begin{tabular}{llllll}
\hline $\begin{array}{l}\text { Predictor } \\
\text { variable }\end{array}$ & $\begin{array}{l}\text { Coefficient of } \\
\text { correlation }\end{array}$ & SE & OR & $\begin{array}{l}\text { 95\% confidence } \\
\text { interval }\end{array}$ & $\boldsymbol{P}$-value \\
\hline $\begin{array}{l}\text { IL-1 } \beta \\
\text { detection }\end{array}$ & 1.20 & 0.39 & 3.32 & 1.54 to 7.19 & 0.002 \\
Age & 0.02 & 0.02 & 1.02 & 0.98 to 1.07 & 0.30 \\
Gender (M) & 0.49 & 0.39 & 1.63 & 0.75 to 3.50 & 0.20 \\
$\begin{array}{l}\text { Disease } \\
\text { duration }\end{array}$ & 0.05 & 0.03 & 1.05 & 0.98 to 1.13 & 0.15 \\
\hline
\end{tabular}

${ }^{\mathrm{a}} \mathrm{LL}-1 \beta$, interleukin $1 \beta ; \mathrm{M}$, male; $\mathrm{OR}$, odds ratio; $\mathrm{SE}$, standard error.

the IL-1 $\beta+$ group. Disease duration also affected OCT parameters (RNFL thickness: $\mathrm{F}=11.50, P=0.001$; $\mathrm{MV}$ : $\mathrm{F}=16.48, P=0.0001)$, with a significant interaction with IL-1 $\beta$ detection (RNFL thickness: $\mathrm{F}=4.46, P=0.03$; MV: $\mathrm{F}=8.07, P=0.005$ ), confirming less severe neurodegenerative damage in participants with undetectable IL-1 $\beta$ in spite of longer disease duration (Figures $4 \mathrm{~A}$ and $4 \mathrm{~B}$ ).

\section{Discussion}

Our aim in the present study was to explore the role of silent inflammation in MS pathophysiology by studying the correlation between CSF IL-1 $\beta$ content at the time of clinical and radiological remission with markers of disease activity, disability progression and neuronal damage $[22,23]$ at midterm follow-up. To the best of our knowledge, herein we report for the first time that the presence of IL- $1 \beta$ in the CSF of RRMS patients at the time of clinical and radiological remission was associated with disability progression and neuronal damage after a median of 5 years of follow-up. Our data show that patients with undetectable CSF levels of IL- $1 \beta$ had a high probability of remaining at low levels of disability, whereas patients with detectable IL-1 $\beta$ had a higher risk for progression of disability and greater restriction in ambulation as measured by both EDSS and MSFC scores. In fact, the probability of reaching an EDSS score of 3 or 4 during follow-up was lower in patients with undetectable IL- $1 \beta$, and undetectable IL- $1 \beta$ significantly predicted benign MS, at equal BREMS scores. Further studies are warranted to confirm our results by means of quantitative PCR. In fact, a more precise cutoff of CSF IL-1 $\beta$ levels below the detection threshold of the immunosorbent assay that we performed could be useful to better identify progression-free patients.

Our OCT measurements of neuronal and axonal damage were in line with these data, as patients with undetectable IL-1 $\beta$ had higher values of RNFL thickness and MV. CSF IL-1 $\beta$ level influenced the risk for disability progression without impacting clinical and radiological markers of inflammatory activity. These data shed new light on our understanding of the disease mechanisms in MS. They suggest that in fact a complete resolution of inflammation after a relapse, as reflected by undetectable presence of IL- $1 \beta$ in the CSF, is potentially a determining factor in midterm disability and prognosis for patients with MS. Persistent inflammation during clinical remission has been previously reported. Overexpression of genes related to adhesion, chemotaxis and blood-brain barrier damage, such as matrix metalloproteinase 9 , chemokine (C-C motif) ligand 19 and intercellular adhesion molecule 5 , has been described in patients with remitting MS, suggesting persistent inflammation during clinical remission [24]. In line with this observation, the percentage of CD4 + tumor necrosis factor $\alpha$-positive-IL-2- T cells in the CSF of RRMS patients in clinical remission was increased compared with CSF from patients with noninflammatory disease [15]. Our data support the idea that persisting inflammation during clinical and radiological remission is not just a remnant of the relapse-associated acute inflammation, but is a damaging phenomenon with the potential to lead to significant clinical midterm disease outcomes. Patients with undetectable IL- $1 \beta$ in fact had a higher probability of presenting with a benign MS phenotype. Thus, we hypothesize that when immune challenge becomes chronic instead of being transient, the CNS is chronically exposed to cytokines with maladaptive effects
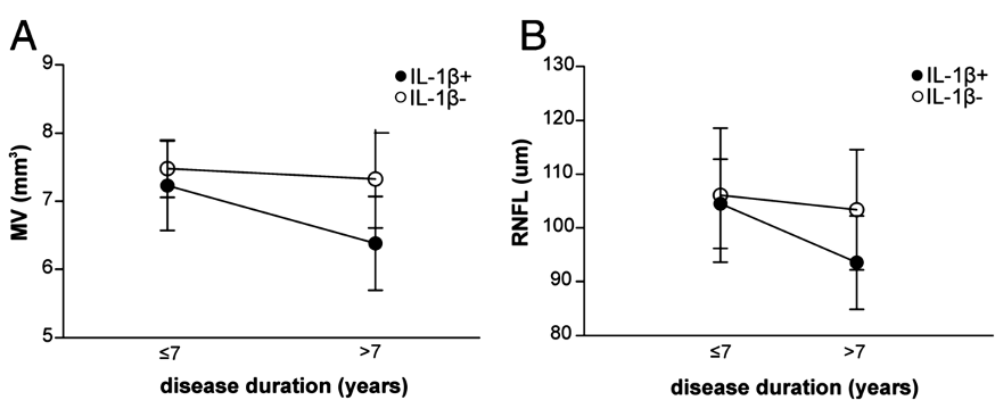

Figure 4 Interleukin $1 \beta$ influences neuronal damage in RR multiple sclerosis. Plots of interaction analysis between interleukin $1 \beta$ (IL-1 $\beta$ ) detection in the cerebrospinal fluid and disease duration, analysis of optical coherence tomography parameters, macular volume (MV) (A) and retinal nerve fiber layer thickness (RNFL) thickness (B). These data confirm the relative preservation of neuronal structures among the participants with undetectable IL-1 $\beta$, despite disease duration. 
such as neuronal and axonal dysfunction evolving to irreversible damage and sustained neurological disability. Long-term disability progression in patients with relap se-onset MS is correlated with degree of disability after 5 years [25], relapse frequency and interval between relapses during the first 2 years [26] and incomplete recovery from relapses during the first 5 years after onset [27]. Nonclinical early predictors of long-term disability have also been identified: brain atrophy rate [28-31], baseline lesion volume [31,32] and long-term increase in lesion volume [30-33]. More recently, long-term disability has also been correlated to measures of gray matter atrophy [34-36] and altered evoked potentials [37-39]. Further research is needed to clarify the source of proinflammatory cytokines during apparent clinical and radiological remission to better define the role of smoldering inflammation in long-term accumulation of neuronal damage and disability.

\section{Conclusions}

We propose that predicting a long-term good prognosis in RRMS would require evidence for complete inflammation resolution during remission in addition to the criteria of disease-free status as recently defined [40].

\section{Competing interests}

SR received honoraria for writing from Bayer Schering and funding for traveling from Novartis, Teva and Merck Serono. She acted as an advisory board member of Biogen Idec and is involved as a subinvestigator in clinical trials for Novartis, Merck Serono, Teva, Bayer Schering, Sanofi-aventis, Biogen Idec and Roche. VDC received funding for traveling by Teva. She is involved as study coordinator in clinical trials for Novartis, Merck Serono, Teva, Bayer Schering, Sanofi-aventis, Biogen Idec and Roche. DC served as an advisory board member of Merck-Serono, Teva, Bayer Schering, Biogen Idec, Novartis and Almirall and received funding for travel, honoraria for speaking or consultation fees from Merck Serono, Teva, Novartis, Bayer Schering, Sanofiaventis and Biogen Idec. He is the Principal Investigator in clinical trials for Novartis, Merck Serono, Teva, Bayer Schering, Sanofi-aventis, Biogen Idec and Roche. The other authors declare that they have no competing interests.

\section{Authors' contributions}

SR and DC were involved in study concept and design. VS, CM, GG, GM, FB, $R M, M C$ and VD were involved in the acquisition of data. SR, SW and DC analyzed and interpreted data. SR and SW drafted the manuscript. Statistical analysis was performed by SR. DC critically revised the manuscript for important intellectual content. All authors read and approved the final manuscript.

\section{Acknowledgements}

The present investigation was funded by a grant from Fondazione Italiana Sclerosi Multipla (Progetto Speciale FISM, 2012/S/2) and by a grant from Ministero della Salute to DC

\section{Author details}

'Clinica Neurologica, Dipartimento di Medicina dei Sistemi, Università Tor Vergata, Via Montpellier 1, 00133 Rome, Italy. ${ }^{2}$ Fondazione Santa Lucia/ Centro Europeo per la Ricerca sul Cervello (CERC), Via del Fosso di Fiorano 64, 00143 Rome, Italy. ${ }^{3}$ Clinica Oculistica, Dipartimento di Medicina Sperimentale e Chirurgia, Università Tor Vergata, Via Montpellier 1, 00133 Rome, Italy. ${ }^{4}$ Neuroimmunology Unit, Institute of Experimental Neurology (INSpe), Division of Neuroscience, San Raffaele Scientific Institute, Via Olgettina 58, 20132 Milan, Italy.
Received: 25 October 2013 Accepted: 30 January 2014

Published: 18 February 2014

\section{References}

1. Rudick RA, Fisher E, Lee JC, Simon J, Jacobs L, Multiple Sclerosis Collaborative Research Group: Use of the brain parenchymal fraction to measure whole brain atrophy in relapsing-remitting MS. Neurology 1999, 53:1698-1704.

2. Rudick RA, Fisher E, Lee JC, Duda JT, Simon J: Brain atrophy in relapsing multiple sclerosis: relationship to relapses, EDSS, and treatment with interferon $\beta$-1a. Mult Scler 2000, 6:365-372.

3. Bjartmar C, Kidd G, Mörk S, Rudick R, Trapp BD: Neurological disability correlates with spinal cord axonal loss and reduced $\mathrm{N}$-acetyl aspartate in chronic multiple sclerosis patients. Ann Neurol 2000, 48:893-901.

4. Peterson JW, Bö L, Mörk S, Chang A, Trapp BD: Transected neurites, apoptotic neurons, and reduced inflammation in cortical multiple sclerosis lesions. Ann Neurol 2001, 50:389-400.

5. Meyer R, Weissert R, Diem R, Storch MK, de Graaf KL, Kramer B, Bähr M: Acute neuronal apoptosis in a rat model of multiple sclerosis. J Neurosci 2001, 21:6214-6220.

6. Cifelli A, Arridge M, Jezzard P, Esiri MM, Palace J, Matthews PM: Thalamic neurodegeneration in multiple sclerosis. Ann Neurol 2002, 52:650-653.

7. $B \varnothing L$, Vedeler CA, Nyland HI, Trapp BD, Mørk SJ: Subpial demyelination in the cerebral cortex of multiple sclerosis patients. J Neuropathol Exp Neurol 2003, 62:723-732.

8. Wegner C, Esiri MM, Chance SA, Palace J, Matthews PM: Neocortical neuronal, synaptic, and glial loss in multiple sclerosis. Neurology 2006, 67:960-967.

9. Vercellino M, Plano F, Votta B, Mutani R, Giordana MT, Cavalla P: Grey matter pathology in multiple sclerosis. J Neuropathol Exp Neurol 2005, 64:1101-1107.

10. Pitt D, Werner P, Raine CS: Glutamate excitotoxicity in a model of multiple sclerosis. Nat Med 2000, 6:67-70.

11. Werner P, Pitt D, Raine CS: Glutamate excitotoxicity —a mechanism for axonal damage and oligodendrocyte death in multiple sclerosis? J Neural Transm Supp/ 2000, 60:375-385.

12. Domercq M, Etxebarria E, Pérez-Samartín A, Matute C: Excitotoxic oligodendrocyte death and axonal damage induced by glutamate transporter inhibition. Glia 2005, 52:36-46.

13. Rossi S, Furlan R, De Chiara V, Motta C, Studer V, Mori F, Musella A, Bergami A, Muzio L, Bernardi G, Battistini L, Martino G, Centonze D: Interleukin-1 $\beta$ causes synaptic hyperexcitability in multiple sclerosis. Ann Neurol 2012, 71:76-83.

14. Polman CH, Reingold SC, Edan G, Filippi M, Hartung HP, Kappos L, Lublin FD, Metz LM, McFarland HF, O'Connor PW, Sandberg-Wollheim M Thompson AJ, Weinshenker BG, Wolinsky JS: Diagnostic criteria for multiple sclerosis: 2005 revisions to the "McDonald criteria". Ann Neurol 2005, 58:840-846.

15. Shi N, Kawano Y, Matsuoka T, Mei F, Ishizu T, Ohyagi Y, Kira J: Increase of CD4 + TNFa + IL-2-T cells in cerebrospinal fluid of multiple sclerosis patients. Mult Scler 2009, 15:120-123.

16. Bergamaschi R, Quaglini S, Trojano M, Amato MP, Tavazzi E, Paolicelli D, Zipoli V, Romani A, Fuiani A, Portaccio E, Berzuini C, Montomoli C, Bastianello S, Cosi V: Early prediction of the long term evolution of multiple sclerosis: the Bayesian Risk Estimate for Multiple Sclerosis (BREMS) score. J Neurol Neurosurg Psychiatry 2007, 78:757-759.

17. Kurtzke JF: Rating neurologic impairment in multiple sclerosis: an Expanded Disability Status Scale (EDSS). Neurology 1983, 33:1444-1452.

18. Roxburgh RH, Seaman SR, Masterman T, Hensiek AE, Sawcer SJ, Vukusic S, Achiti I, Confavreux C, Coustans M, le Page E, Edan G, McDonnell GV, Hawkins S, Trojano M, Liguori M, Cocco E, Marrosu MG, Tesser F, Leone MA, Weber A, Zipp F, Miterski B, Epplen JT, Oturai A, Sørensen PS, Celius EG, Lara NT, Montalban X, Villoslada P, Silva AM, et al: Multiple sclerosis severity score: using disability and disease duration to rate disease severity. Neurology 2005, 64:1144-1151.

19. Cutter GR, Baier ML, Rudick RA, Cookfair DL, Fischer JS, Petkau J, Syndulko K, Weinshenker BG, Antel JP, Confavreux C, Ellison GW, Lublin F, Miller AE, Rao SM, Reingold S, Thompson A, Willoughby E: Development of a multiple sclerosis functional composite as a clinical trial outcome measure. Brain 1999, 122:871-882

20. Rossi S, Mancino R, Bergami A, Mori F, Castelli M, De Chiara V, Studer V, Mataluni G, Sancesario G, Parisi V, Kusayanagi H, Bernardi G, Nucci C, 
Bernardini S, Martino G, Furlan R, Centonze D: Potential role of IL-13 in neuroprotection and cortical excitability regulation in multiple sclerosis. Mult Scler 2011, 17:1301-1312.

21. Lublin FD, Reingold SC, National Multiple Sclerosis Society (USA) Advisory Committee on Clinical Trials of New Agents in Multiple Sclerosis: Defining the clinical course of multiple sclerosis: results of an international survey. Neurology 1996, 46:907-911.

22. Sergott RC, Frohman E, Glanzman R, Al-Sabbagh A, OCT in MS Expert Panel: The role of optical coherence tomography in multiple sclerosis: expert panel consensus. J Neurol Sci 2007, 263:3-14.

23. Petzold A, de Boer JF, Schippling S, Vermersch P, Kardon R, Green A, Calabresi PA, Polman C: Optical coherence tomography in multiple sclerosis: a systematic review and meta-analysis. Lancet Neurol 2010, 9:921-932. A published erratum appears in Lancet Neurol 2010, 9:1045.

24. Gurevich M, Achiron A: The switch between relapse and remission in multiple sclerosis: continuous inflammatory response balanced by Th1 suppression and neurotrophic factors. J Neuroimmunol 2012, 252:83-88.

25. Kurtzke JF, Beebe GW, Nagler B, Kurland LT, Auth TL: Studies on the natural history of multiple sclerosis. 8. Early prognostic features of the later course of the illness. J Chronic Dis 1977, 30:819-830.

26. Weinshenker BG, Bass B, Rice GP, Noseworthy J, Carriere W, Baskerville J, Ebers GC: The natural history of multiple sclerosis: a geographically based study. 2. Predictive value of the early clinical course. Brain 1989, 112:1419-1428.

27. Runmarker $B$, Andersen $O$ : Prognostic factors in a multiple sclerosis incidence cohort with twenty-five years of follow-up. Brain 1993, 116:117-134.

28. Fisher E, Rudick RA, Simon JH, Cutter G, Baier M, Lee JC, Miller D, WeinstockGuttman B, Mass MK, Dougherty DS, Simonian NA: Eight-year follow-up study of brain atrophy in patients with MS. Neurology 2002, 59:1412-1420.

29. Lin X, Blumhardt LD, Constantinescu CS: The relationship of brain and cervical cord volume to disability in clinical subtypes of multiple sclerosis: a three-dimensional MRI study. Acta Neurol Scand 2003, 108:401-406.

30. Lukas C, Minneboo A, de Groot V, Moraal B, Knol DL, Polman CH, Barkhof F, Vrenken $\mathrm{H}$ : Early central atrophy rate predicts 5 year clinical outcome in multiple sclerosis. J Neurol Neurosurg Psychiatry 2010, 81:1351-1356.

31. Popescu V, Agosta F, Hulst HE, Sluimer IC, Knol DL, Sormani MP, Enzinger C, Ropele S, Alonso J, Sastre-Garriga J, Rovira A, Montalban X, Bodini B, Ciccarelli O, Khaleeli Z, Chard DT, Matthews L, Palace J, Giorgio A, De Stefano N, Eisele P, Gass A, Polman CH, Uitdehaag BM, Messina MJ, Comi G, Filippi M, Barkhof F, Vrenken H, MAGNIMS Study Group: Brain atrophy and lesion load predict long term disability in multiple sclerosis. J Neurol Neurosurg Psychiatry 2013, 84:1082-1091.

32. Fisniku LK, Brex PA, Altmann DR, Miszkiel KA, Benton CE, Lanyon R, Thompson AJ, Miller DH: Disability and T2 MRI lesions: a 20-year follow-up of patients with relapse onset of multiple sclerosis. Brain 2008, 131:808-817.

33. Brex PA, Ciccarelli O, O'Riordan Jl, Sailer M, Thompson AJ, Miller DH: A longitudinal study of abnormalities on MRI and disability from multiple sclerosis. N Engl J Med 2002, 346:158-164.

34. Fisniku LK, Chard DT, Jackson JS, Anderson VM, Altmann DR, Miszkiel KA, Thompson AJ, Miller DH: Gray matter atrophy is related to long-term disability in multiple sclerosis. Ann Neurol 2008, 64:247-254. A published erratum appears in Ann Neurol 2009, 65:232.

35. Horakova D, Dwyer MG, Havrdova E, Cox JL, Dolezal O, Bergsland N, Rimes B, Seidl Z, Vaneckova M, Zivadinov R: Gray matter atrophy and disability progression in patients with early relapsing-remitting multiple sclerosis: a 5-year longitudinal study. J Neurol Sci 2009, 282:112-119.

36. Rudick RA, Lee JC, Nakamura K, Fisher E: Gray matter atrophy correlates with MS disability progression measured with MSFC but not EDSS. J Neurol Sci 2009, 282:106-111.

37. Fuhr P, Borggrefe-Chappuis A, Schindler C, Kappos L: Visual and motor evoked potentials in the course of multiple sclerosis. Brain 2001, 124:2162-2168.
38. Kallmann BA, Fackelmann S, Toyka KV, Rieckmann P, Reiners K: Early abnormalities of evoked potentials and future disability in patients with multiple sclerosis. Mult Scler 2006, 12:58-65.

39. Schlaeger R, D'Souza M, Schindler C, Grize L, Dellas S, Radue EW, Kappos L, Fuhr P: Prediction of long-term disability in multiple sclerosis. Mult Scler 2012, 18:31-38.

40. Havrdova E, Galetta S, Stefoski D, Comi G: Freedom from disease activity in multiple sclerosis. Neurology 2010, 74(Suppl 3):S3-S7.

doi:10.1186/1742-2094-11-32

Cite this article as: Rossi et al:: Cerebrospinal fluid detection of interleukin- $1 \beta$ in phase of remission predicts disease progression in multiple sclerosis. Journal of Neuroinflammation 2014 11:32.

\section{Submit your next manuscript to BioMed Central and take full advantage of:}

- Convenient online submission

- Thorough peer review

- No space constraints or color figure charges

- Immediate publication on acceptance

- Inclusion in PubMed, CAS, Scopus and Google Scholar

- Research which is freely available for redistribution

Submit your manuscript at www.biomedcentral.com/submit
C) BioMed Central 